\title{
Eco-Friendly Pretreatment of Cotton Fabric With Banana Ash and Dyeing Using Banana Sap
}

\author{
Avik Kumar Dhar (M. Sc. in Textile Engineering) \\ University of South Asia, Bangladesh \\ Maitry Bhattacharjee (B. Sc. in Textile Engineering) \\ Shyamoli Textile Engineering College, University of Dhaka, Bangladesh \\ Most. Mahfuza Rima (B. Sc. in Textile Engineering) \\ Textile Engineering College, Zorargonj, Chittagong, Bangladesh \\ Muhammad Abdur Rashid (M. Sc. in Textile Engineering) \\ Dhaka University of Engineering \& Technology (DUET), Bangladesh \\ doi: 10.19044/esj.2017.v13n27p390 URL:http://dx.doi.org/10.19044/esj.2017.v13n27p390

\begin{abstract}
The aim of this study is to evaluate environment supportive pretreatment and dyeing process. In this project, pretreatment of cotton fabric was done by using banana ash. Also, dyeing was carried out with banana sap along with different mordants that are eco-friendly and cost saving. Here, all the experiments were carried out on woven (plain) fabric of 141 GSM. Firstly, cotton fabric was scoured by means of banana root's ash (pH-10.2). It was then dyed with banana sap (pH-5.4). This banana ash scoured cotton fabric was compared with conventionally scoured cotton fabric through weight loss \% and absorbency test. In addition, fastness properties and performance of dyeing were measured through CIE $\mathrm{L}^{*} \mathrm{C}^{*} \mathrm{~h}, \mathrm{~K} / \mathrm{S}$ value, and different color fastness tests. Banana ash scoured and dyed with banana sap, using mordant (horitoky), provided the best dyeing performance and color fastness to wash, rubbing, and perspiration than the others.
\end{abstract}

Keywords: Eco-friendly, Banana root's Ash, Banana Sap, Scouring, Color fastness

\section{Introduction}

Scouring is the most important wet process applied to textile materials before dyeing or printing. It is mostly a cleaning process in which unexpected oils, fats, waxes, solid dirts, soluble and natural impurities are removed. Basically, good scouring is considered as the foundation of successful dyeing, printing, and finishing (M. Clark et al., 2011). In synthetic chemical pretreatment, different scouring materials have been used in the 
textile industries like $\mathrm{NaCO}_{3}, \mathrm{Ca}(\mathrm{OH})_{2}, \mathrm{NaOH}$ etc. Typically, conventional chemical scouring has been carried out in hot $\left(90^{\circ} \mathrm{C}-100^{\circ} \mathrm{C}\right) \mathrm{NaOH}$ solution for 45-60 minutes. However, the conditions depend on the quality of scoured fabric required (A. M. K. Bahrum Prang Rocky, 2012). The use of highly toxic chemicals increases the volume of effluents and causes environmental pollution. As a result of this, researcher were looking forward to having ecofriendly and sustainable textile processes. From this point of view, they added a new line of research and paid concentration on enzymatic scouring process. Enzymes, generally, act in low temperature with first-rate efficacy. It saves high cost of energy consumption compared to conventional process. Moreover, it reduces Biological Oxygen Demand (BOD) and Chemical Oxygen Demand (COD), TDS, and other waste water effluent load thus reduces ETP operational cost. For enzyme scouring, pectinase was the only enzyme needed for wettability/ dyeability. The bioscoured fabric provided a softer feel than the convencional caustic soda scouring process. However, the degree of whiteness was often less, and seed coat fragments were not satisfactorily removed. The most crucial factor in the whole bioscouring process was the removal of the enzyme-weakened cuticle compounds in the rinsing phase. Rinsing at high temperatures in the presence of surfactant and EDTA was most competent (Lenting \& Zwier, 2002 ). In general, enzymatic scourings did not give better results (Karapinar \& Sariisik, 2004) than conventional alkaline scouring. However, almost similar results to conventional scouring by means of wettability and pectin removal were achieved with the combination of cellulase and pectinase and cellulose, protease and pectinase. To avoid the intricacy of enzyme treatment, researchers started to implement the natural resources to make the overall process eco-friendly and to set example of Green textile. Nature has adorned this unique world with a lot of incredible resources. As a noteworthy resource of nature, banana plant were investigated. Furthermore, banana flower was declared as a treatment of different chronic diseases like bronchitis, dysentery, ulcers, diabetics, and plant sap in cases of hysteria, epilepsy, leprosy, fevers, hemorrhages, actue dysentery, and diarrhea (K. P. Sampath Kumar et al., 2012). Banana plant has made significant contribution not only in the medical sector, but also in the textile sector. A study was carried out to explore the potential of banana sap as a dye for the Adinkra industry in Ghana. Pseudostem extract of banana and stem bark extract of Bridelia micratha were compared as dyeing stuff (BM Dzomeku \& OK Boateng, 2012). Antibacterial and UV protective properties of banana peel, antioxidant, and antimicrobial properties of banana ash were explored also. Besides, the properties of banana fiber reinforced composites were also studied, and the variation in the mechanical properties were also analysed (J.Santhosh et al., 2014). In this study, pretreatment of cotton fabric was 
attempted to be carried out with banana root's ash and dyeing with banana sap. Therefore, this was extracted from banana plant bark to overcome the harmful effect of synthetic chemicals and also the complexity of enzyme and other applications. Optimum quality needs to be checked also.

\section{Materials}

Table 1. Fabric specification

Types of Fabric

GSM

EPI

PPI

Warp count

Weft count
Woven (plain)

141

50

50

$20^{\mathrm{s}}$

$17^{\mathrm{s}}$

\section{Chemicals}

Table 2. List of chemicals for different processes

\begin{tabular}{|c|c|c|c|}
\hline Process & Chemicals & $\begin{array}{c}\text { Commercial } \\
\text { Name/Brand Name }\end{array}$ & $\begin{array}{c}\text { Company/Suppli } \\
\text { er/Country }\end{array}$ \\
\hline \multirow{5}{*}{ Pretreatment } & Wetting agent & DYNOTEX MH-40 & China \\
\cline { 2 - 4 } & Banana ash & Natural source & Bangladesh \\
\cline { 2 - 4 } & Sequestering Agent & MASQUOL P 210N & China \\
\cline { 2 - 4 } & Acetic Acid & Merck & Germany \\
\cline { 2 - 4 } & Sodium Hydroxide & Natrium hydroxide & $\begin{array}{c}\text { MERCK, } \\
\text { India/James } \\
\text { corporation }\end{array}$ \\
\hline \multirow{4}{*}{ Dyeing } & Banana sap & Natural Source & Bangladesh \\
\cline { 2 - 4 } & Sequestering Agent & MASQUOL P 210N & China \\
\cline { 2 - 4 } & Wetting agent & DYNOTEX MH-40 & China \\
\hline
\end{tabular}

\section{Method}

Pretreatment

Recipe

Wetting agent $-1 \mathrm{~g} / \mathrm{l}$

Sequestering Agent - 2g/l

Banana Ash - 60g/l

Time - 45min

M:L - 1:30 


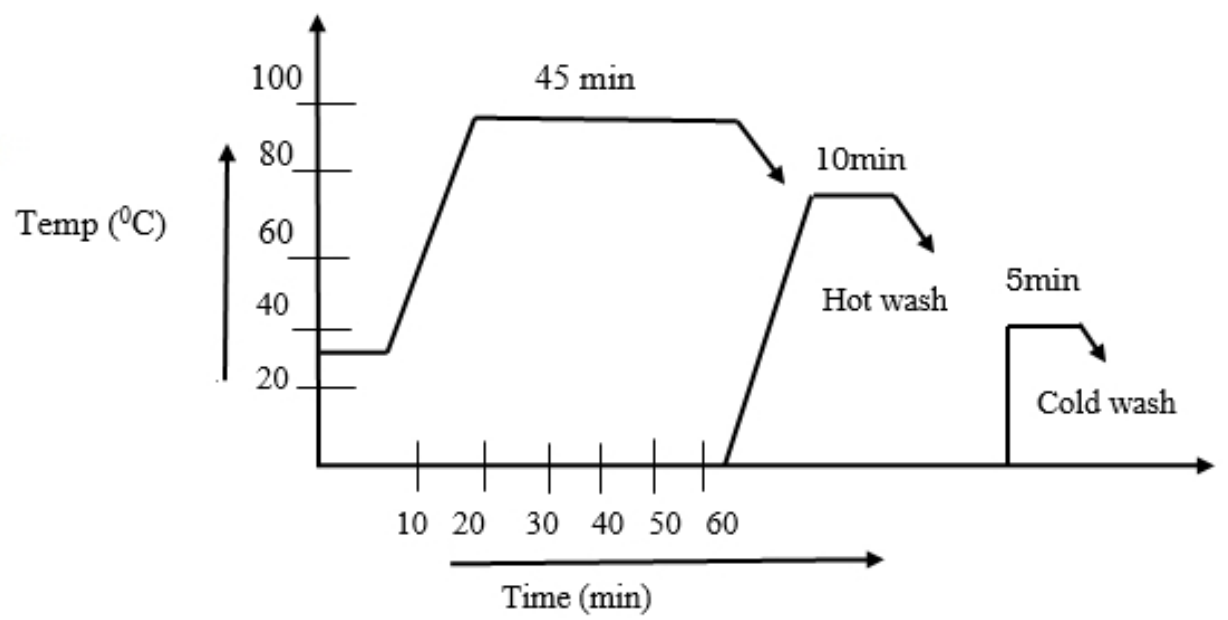

Figure 1. Process curve of Scouring with Banana Ash

\section{Dyeing}

Recipe

Banana Sap - 40ml

Fabric Weight - 5g

Sequestering Agent - 2g/l

Wetting Agent $-1 \mathrm{~g} / \mathrm{l}$

Temperature $-95^{\circ} \mathrm{C}$

Time - 40min

M:L - 1:30

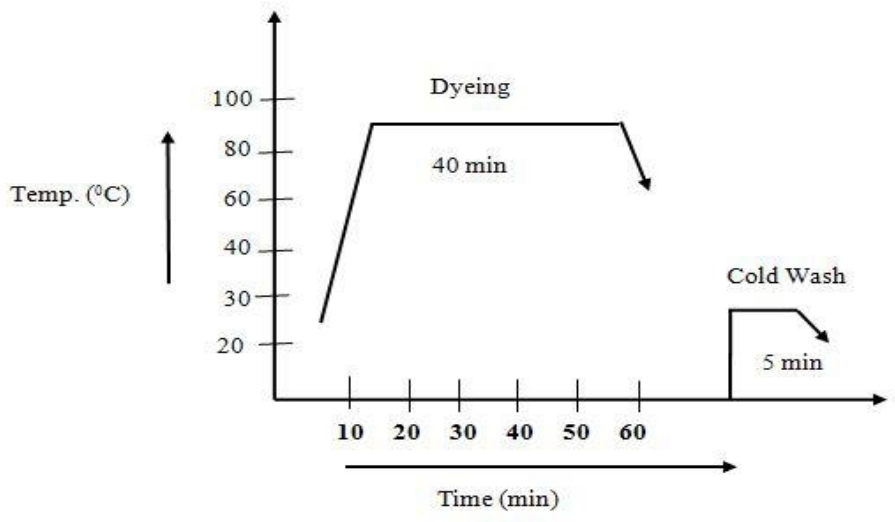

Figure 2. Process Curve of Dyeing with Banana Sap

Banana sap is collected from the banana tree through manual process. Then the recipe was prepared and the fabric was dyed without mordant and with mordant. Hence, mordant Potash Alum and Horitoky were 
used. Overall, 4 different samples were found as follows: Sample A was conventionally scoured and dyed with banana sap without mordant. Sample B, Banana ash scoured and dyed with banana sap without mordant. Sample C, Banana ash scoured and dyed with banana sap using mordant (alum). Finally, Sample D, Banana ash scoured and dyed with banana sap using mordant (horitoky). Meta-mordanting (metachrome) was carried out where the mordant is added in the dye bath itself.

\title{
Experimentals
}

\section{Determination of Weight Loss \%}

The main changes which occur in cotton goods during scouring process is weight loss due to the removal of natural impurities (fats, waxes, etc). However, the range of weight loss is about 5-10\%.

Percentage $(\%)$ weight loss of the sample was measured using the following equation:

(sample weight before scouring- sample weight after scouring)

sample weight before scouring

\begin{abstract}
Absorbency Test
Absorbency test is carried out to measure the proclivity of fabric to take up water through AATCC test method 79. Scoured sample was placed in an embroidery hoop with all creases out of it. A burette dispensed a drop of water onto the surface of the fabric from a distance of $9.5 \mathrm{~mm}$ below the burette. Time was recorded until the drop absorbs completely.
\end{abstract}

\section{K/S Determination}

Tinctorial value or color strength $(\mathrm{K} / \mathrm{S})$ is considered as the most important parameter to test the quality measurement of a sample in terms of the depth of the color dyed fabric. The color strength of a dyed fabric is usually pronounced by its K/S value. Color strength, or tinctorial value of a pigment, is defined as its ability to impart color to other materials. The lower the concentration required by a colored pigment to achieve a defined impression of color, that is, a given depth of a shade, the greater the color strength of the colored pigments. It depends on the absorption coefficient $(\mathrm{K})$ of colorant and the scattering coefficient $(\mathrm{S})$. Consequently, the strength of any colorant (dyestuff / pigment) is related to absorption property. Reflectance $(\%)$ of the dyed fabric samples were measured by using Data color 650 TM spectrophotometer. Kubelka - Munk theory provides the following relation between reflectance and absorbance:

$$
\mathbf{K} / \mathbf{S}=\left[\left\{(1-R)^{2} / 2 R\right\}\right]
$$


Where $\mathrm{R}$ is the reflectance, $\mathrm{K}$ is absorbance, and $\mathrm{S}$ is the scattering. $\mathrm{K} / \mathrm{S}$ versus Wavelength curve is always the characteristics of every colorant.

\section{Color Fastness Test}

Color fastness is a term used in the dyeing of textile materials that characterizes a material's color resistance to fading or running. Different color fastness tests were carried out such as color fastness to wash, color fastness to rubbing (dry and wet), and then color fastness to perspiration (acid) through ISO method. Wash fastness test was also carried out through ISO-105-C03 method treating $10 \mathrm{~cm} \times 4 \mathrm{~cm}$ sized composite sample (sample fabric and DW multifiber fabric) with soap solution in rota wash machine. Furthermore, the fastness rating by using color fading grey scale and color staining grey scale in color matching cabinet was also evaluated. In addition, rubbing fastness was carried out by ISO-105-X12 method (Dry and Wet) taking a sample size of $14 \mathrm{~cm} \times 5 \mathrm{~cm}$. Hand crank is turned 10 times at the rate of $1 \mathrm{turn} / \mathrm{sec}$ and fastness rating was then evaluated by color staining grey scale. In addition, ISO-105-E04 method was followed for testing color fastness to perspiration (acid).

\section{Color Difference by CMC DE}

The CMC system was actually developed by R McDonald. Later, it was recommended by the Colour Matching Committee of the SDC with only minor modifications. In this color space, $\mathrm{L}^{*}$ indicates lightness, $\mathrm{C}^{*}$ represents chroma, and $\mathrm{h}$ is the hue angle. The value of chroma $\mathrm{C}^{*}$ is the distance from the lightness axis $\left(\mathrm{L}^{*}\right)$ and it starts at 0 in the center. Hue angle starts at the $+\mathrm{a}^{*}$ axis and is expressed in degrees (e.g., $0^{\circ}$ is $+\mathrm{a}^{*}$, or red, and $90^{\circ}$ is $+\mathrm{b}$, or yellow).

$\mathrm{L}^{*}=$ lightness

$\mathrm{C}^{*}=$ chroma

$\mathrm{h}=$ hue

Color difference is defined as the numerical comparison of a sample to the standard. Referred to as Delta $(\Delta)$, it indicates the differences in absolute color coordinates. Deltas for lightness $\left(\Delta \mathrm{L}^{*}\right)$, chroma $\left(\Delta \mathrm{C}^{*}\right)$, and hue $\left(\Delta \mathrm{H}^{*}\right)$ may be positive $(+)$ or negative $(-)$.

$\Delta \mathrm{L}^{*}=$ difference in lightness and darkness $(+=$ lighter, $-=$ darker $)$

$\Delta \mathrm{C}^{*}=$ difference in chroma $(+=$ brighter, $-=$ duller $)$

$\Delta \mathrm{H}^{*}=$ difference in hue 


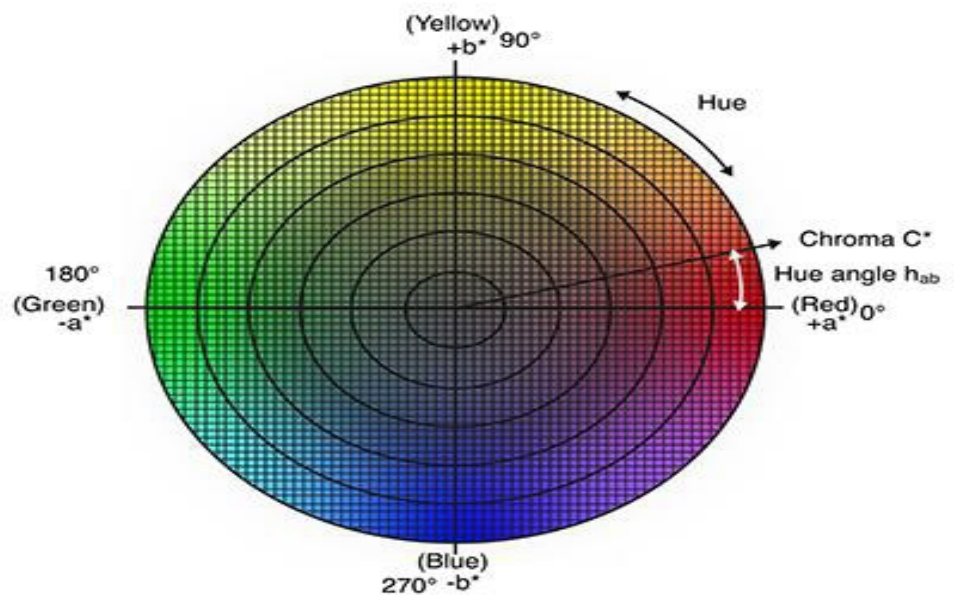

\section{Results and Discussions}

Comparison of Weight Loss \% between Different Pretreatment Options

\section{Weight Loss\%}

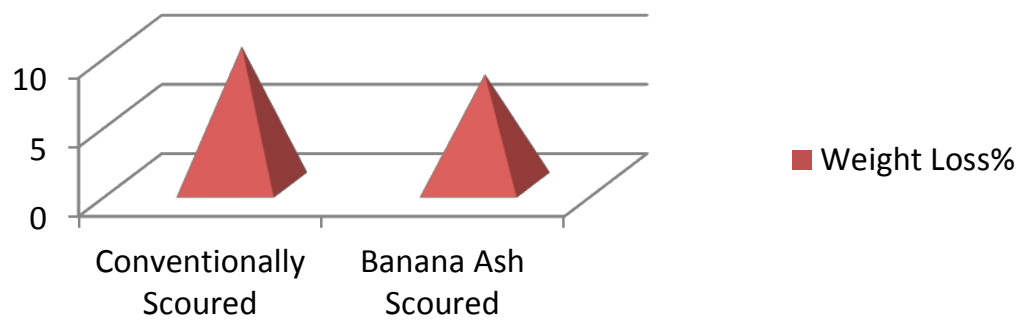

Figure 3. Graphical representation of weight loss \%

Standard range of weight loss is $4-8 \%$. Weight loss \% of banana ash scoured fabric is excellent and it reduce the possibilities of over scouring and fabric damages.

\section{Comparison of Absorbency of Different Pretreatment Options}

Fabric scoured with banana ash took 20-25 seconds to absorb water. On the other hand, chemical scoured fabric absorbed water within 5-10 seconds. 


\section{Results of K/S Value of Different Dyed Samples}

\section{$\mathrm{K} / \mathrm{S}$ value}

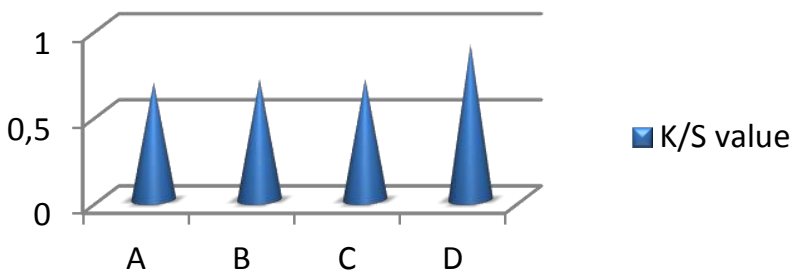

Figure 4. K/S Values of different samples

Graphical presentation shows that the highest K/S value is obtained in the case of Sample D. Here, the fabric was scoured with Banana ash and dyed with banana sap using horitoky as the mordant.

\section{Comparison of Color Fastness to Wash}

Test of color fastness to wash was carried out and the best result was obtained (both in color fading and color staining). This was seen in the case of the sample scoured with banana ash and dyed with banana sap in the presence of horitoky as a mordant.

Table 3. Comparison of color fastness to wash of differently dyed samples

\begin{tabular}{|c|c|c|c|c|c|c|c|}
\hline \multirow{2}{*}{ Samples } & \multirow{2}{*}{ Fading } & \multicolumn{6}{|c|}{ Staining } \\
\cline { 3 - 8 } & & Acetate & Cotton & Nylon & Polyester & Acrylic & Wool \\
\hline $\mathrm{A}$ & 4 & $1 / 2$ & 4 & 2 & $4 / 5$ & 5 & $4 / 5$ \\
\hline $\mathrm{B}$ & 4 & 2 & $4 / 5$ & 2 & 5 & 5 & $4 / 5$ \\
\hline $\mathrm{C}$ & $4 / 5$ & $1 / 2$ & $4 / 5$ & $2 / 3$ & 5 & 5 & $4 / 5$ \\
\hline $\mathrm{D}$ & 5 & $2 / 3$ & $4 / 5$ & $4 / 5$ & 5 & 5 & $4 / 5$ \\
\hline
\end{tabular}

\section{Comparison of Color Fastness to Rubbing}

Best result of color fastness to rubbing (both in dry and wet) was obtained in case of Sample B. Here, the fabric was scoured with Banana ash and dyed with banana sap without mordant. Same rating was found in case of sample D also. In this case, the sample was scoured with banana ash and dyed with banana sap along with a natural mordant, horitoky.

Table 4. Comparison of color fastness to rubbing of differently dyed samples

\begin{tabular}{|c|c|c|}
\hline Samples & Dry Rubbing & Wet Rubbing \\
\hline A & 4 & 3 \\
\hline B & $4 / 5$ & 4 \\
\hline C & $4 / 5$ & 4 \\
\hline D & $4 / 5$ & 4 \\
\hline
\end{tabular}




\section{Comparison of Color Fastness to Perspiration}

Color fastness to persipiration (acid) was carried out through ISO recommended process. Also, superior rating was found in case of sample D (scoured with banana ash and dyed with banana sap along with horitoky as a mordant).

Table 5. Comparison of color fastness to Perspiration of differently dyed samples

\begin{tabular}{|c|c|c|c|c|c|c|c|}
\hline \multirow{2}{*}{ Samples } & \multirow{2}{*}{ Fading } & \multicolumn{6}{|c|}{ Staining } \\
\cline { 3 - 8 } & & Acetate & Cotton & Nylon & Polyester & Acrylic & Wool \\
\hline $\mathrm{A}$ & $4 / 5$ & $4 / 5$ & $4 / 5$ & 4 & 4 & $4 / 5$ & $4 / 5$ \\
\hline $\mathrm{B}$ & 5 & $4 / 5$ & $4 / 5$ & 3 & $4 / 5$ & $4 / 5$ & 5 \\
\hline $\mathrm{C}$ & 5 & 4 & $4 / 5$ & 4 & 4 & $4 / 5$ & 4 \\
\hline $\mathrm{D}$ & 5 & 5 & 5 & $4 / 5$ & $4 / 5$ & 5 & $4 / 5$ \\
\hline
\end{tabular}

\section{Color Difference}

Datacolor Spectrophotometer was used to measure the CMC value of different samples. Sample A was considered as the standard, and the CMC values of different samples were measured. Finding states that, comparatively, best result was found in the case of sample D and its rating was 0.43 which is less than 1 .

Table 6. CMC $\mathrm{L} * \mathrm{C} * \mathrm{~h}$ values of different samples

\begin{tabular}{|c|c|c|c|}
\hline Samples & L $^{*}$ & $\mathrm{C}^{*}$ & $\mathrm{~h}$ \\
\hline $\mathrm{A}$ & 74.147 & 10.633 & 72.158 \\
\hline $\mathrm{B}$ & 74.917 & 11.893 & 72.291 \\
\hline $\mathrm{C}$ & 72.557 & 12.273 & 74.518 \\
\hline $\mathrm{D}$ & 74.683 & 10.858 & 71.034 \\
\hline
\end{tabular}

\section{CMC Value}

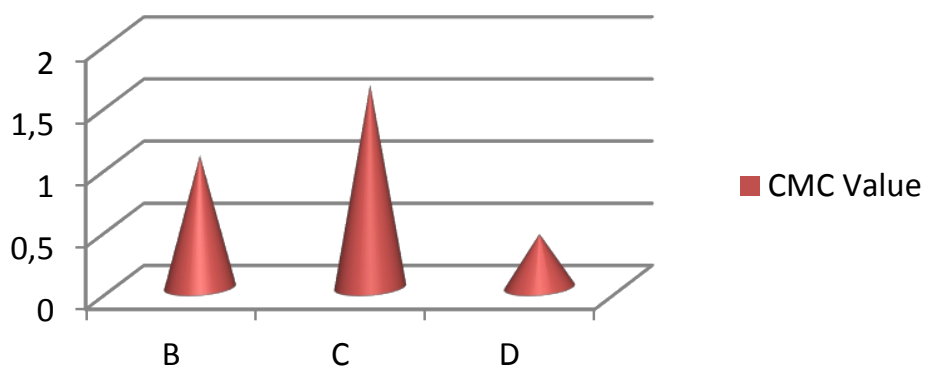

Figure 5. Graphical representation of CMC Value

\section{Conclusion}

In favour of the environment, this project ensures natural scouring and dyeing processes which were done by banana ash and banana sap. The 
experimental data shows the suitability of natural process over the existing process. Environment pollution, effluent rate, and health hazard can be extirpated in performing the processes using the easiest way and resources. In this project, it was shown that scouring of cotton fabric with banana ash result in $8 \%$ weight loss. Whereas in case of conventional scouring $(\mathrm{NaOH})$, weight loss was calculated as $10 \%$. In addition, dyeing of cotton fabric with banana sap, especially with the presence of horitoky, showed better K/S value, CIE $\mathrm{L}^{*} \mathrm{C}^{*} \mathrm{~h}$ value, and fastness properties than the other samples. Further researches can be carried out on banana sap keeping in mind its ecofriendly nature.

\section{References:}

1. Abrahart, EN, (1997). Stilbene dye and floroscent brightening agent in dyes and tier intermediates, Edward Amold publication, London 178- 184.

2. Bhattacharya, N. (1992). Natural dyes its Authenticity and Identification. Replika press Ltd, New Delhi 134-141.

3. Broadbent, AD. (2001). Basic Principles of Textile Coloration, Bradford, West Yorkshire BD1 2JB, Society of Dyers and Colourists, 29-35/469.

4. Cegarra, J., Puente, P., \& Valldeperas, J. (1992). The Dyeing of Textile Materials; the scientific base and Techniques of Application, Textilia, Biella, Italy.

5. Jahan, M. (2010). Concentration influence on antimicrobial activity of banana blossom extract incorporated chitosan-polyeethylene glycol (CS-PEG) blended film. Journal of chemical and pharmaceutical.

6. Konicaminolta.us (2015). KONICA MINOLTA Official Website. [Online] Available at: http://sensing.konicaminolta.us/understandingthe-cie-lch-color-space/ [Accessed 15 March 2015].

7. M. Clark (2011). Handbook of textile and industrial dyeing, Oxford; Woodhead.

8. Morton, J. (1987). Fruits of Warm Climates, Banana. Miami; Julia F. Morton, p. 29-46.

9. Pothavorn, P., Kitdamrongsont, K., Savasti, and Somana, J. (2010). Sap phytochemical composition of some bananas in Thailand. Journal of Agriculture and Food chemistry 58(15), 8782-8787.

10. Willis, W.B. (1998). The Adinkra Dictionary. The pyramid complex Washington DC 20009, U.S.A; 12-14. 